\title{
Mutation-based PSO techniques for optimal location and parameter settings of STATCOM under generator contingency
}

\author{
Jayachitra Selvaraj ${ }^{*}$ and \\ Amin Salih Mohammed \\ Department of Computer Engineering, \\ College of Engineering and Computer Science, \\ Lebanese French University, \\ Erbil, Iraq \\ Email: jayanethaji@gmail.com \\ Email:kakshar@gmail.com \\ *Corresponding author
}

\begin{abstract}
This article addresses the efficient contribution of particle swarm optimisation (PSO) and its variants such as constrained factor-PSO (CF-PSO), Cauchy mutation-CFPSO (CM-CFPSO) and Gaussian mutation-CFPSO (GM-CFPSO) algorithm to choose suitable placement and rating of static synchronous compensator (STATCOM) based on novel index called unification index (UI). Minimisation of real and reactive power loss, voltage deviation reduction and augmentation of voltage stability are considered for this research work. UI is computed with respect to normal and generator contingency condition. Based on the index value, the ranking of severe lines is made. The purpose of embedding PSO with mutation is to expand the search space particularly to avoid being trapped in local optima. IEEE 30 bus system is chosen to assess the potency of the propound method using MATLAB working platform against generator bus contingency with and without STATCOM. This proposed approach yields promising result and their performances were presented and compared with other methodologies.
\end{abstract}

Keywords: generator contingency; mutation; particle swarm optimisation; PSO; static synchronous compensator; STATCOM; unification index.

Reference to this paper should be made as follows: Selvaraj, J. and Mohammed, A.S. (2020) 'Mutation-based PSO techniques for optimal location and parameter settings of STATCOM under generator contingency', Int. J. Intelligence and Sustainable Computing, Vol. 1, No. 1, pp.53-68.

Biographical notes: Jayachitra Selvaraj is working as an Assistant Professor at the Department of Computer Engineering, Lebanese French University, Erbil. She has experience in teaching for more than 12 years. She completed her graduation in Electrical and Electronics Engineering in 1998, post graduated in Power Electronics and Drives from VIT University, Vellore and $\mathrm{PhD}$ in the area of Hybrid Soft Computing Techniques. Her research interest includes soft computing techniques and FACTS controllers. She has published research articles in various international journals and conferences and a book with a title Flexible AC Transmission System in 2013. 
Amin Salih Mohammed is working as Assistant Professor and Dean of College of Engineering and Computer Science, Lebanese French University, Erbil. He has experience in teaching for more than 15 years. He completed his $\mathrm{PhD}$ in Radio Electronic from Kharkiv National University in 2012. His research interest includes artificial intelligence, computer networks and data security. $\mathrm{He}$ has published research articles in various international journals and conferences.

\section{Introduction}

Power system is a complex network (Paserba, 2010) which is an interconnection of generating resources and consumer loads through a system of transmission lines, transformers. In the latest years, the growing industrialisation along with the rapid urbanisation of society causes vast increase in power demand. This power demand is unmatched with power generation and transmission capacity. Hence, voltage stability has become a most sensitive issue in power systems planning and operation .To satisfy high quality of customer service, magnitude of load voltage must be retained within the permissible range. Due to the scarcity of supplying reactive power sources to maintain normal voltage profiles at heavily loaded buses leads to voltage instability as in Gitizadeh and Kalantar (2008). The voltage instability results as a form of a fall or rise of terminal voltages at some buses. The outcomes of voltage instability are loss of load in interconnected area, or outage of transmission lines and sometimes ending with cascading line outages (Preethi et al., 2011; Banu and Devaraj, 2009).

From the literature survey, it is highly recommended that, power electronics-based controller called flexible AC transmission system (FACTS) controllers which is a concept proposed by N.G. Hingorani, an alternative solution to prevent the voltage block outs and minimises transmission losses. The merits of FACTS controller include less installation cost, operating with none pollution, and providing flexible control of the existing transmission system as in Mishra and Gundavarapu (2016). The basic applications of FACTS controlled are discussed in detail as in Mishra et al. (2016). Parallel connected FACTS controller [static var compensator (SVC) and STATCOM] are playing an important role in reactive power flow control through a transmission line to avoid the voltage fluctuation and to enhance the voltage stability margin. The concern on optimal placement of these controllers at appropriate location is really brainstorming and many strategies have been discussed, proposed and implemented by researchers. If the FACTS devices are fitted at right place, it can amend the line power flows and keep bus voltages at desired level and so improve voltage stability margins and enhance network security as in Roy et al. (2011). Three different objective functions namely, minimisation of real and reactive power loss, voltage deviation reduction and augmentation of voltage stability are considered for this research work. Maximising the voltage stability margin is by reducing the more severe line index value of a given network. The few line stability objective function in the optimal location of the FACTS devices for minimising the power system losses and the voltage stability improvement as in Sundar and Ravikumar (2012).

In this research study contribution is, two separate indices - contingency severity index (CSI) as in Malathy and Shunmugalatha (2016) and voltage collapse proximity 
index (VCPI) as in Naishan et al. (2006) had been fused to formulate a unitification index (UI) to estimate line overloads and bus voltage deviation of the system for correct assessment of severity. Line CSI is used for the measurement of line overloads, where as VCPI had been preferred for voltage contingency ranking because of its simplicity makes numerical calculation easier. The multi objective function consists of minimisation of active and reactive power loss, voltage deviation and voltage stability index. The STATCOM is placed on the most severe load bus. The PSO and its variants are demonstrated during generator bus contingency on IEEE 30 bus system. The simulated results are presented and analysed.

\section{Unification index}

After finding the CSI (Malathy and Shunmugalatha, 2016) and VCPI (Naishan et al., 2006) values of all the transmission for a particular line outage, the UI is evaluated as given in (1) and (2).

$$
\begin{aligned}
& \mathrm{UI}_{\mathrm{uv}}=\mathrm{K}_{1} * \mathrm{CSI}_{\mathrm{uv}}+\mathrm{K}_{2} * \mathrm{VCPI}_{\mathrm{uv}} \\
& \mathrm{UI}_{\text {Overall }}=\sum_{\substack{\mathrm{u}=1 \\
\mathrm{u}=\mathrm{PQbus}}}^{\mathrm{u}=\mathrm{N}_{\mathrm{PQ}}}\left(\mathrm{UI}_{\mathrm{uv}}\right) \\
& \mathrm{K}_{1}+\mathrm{K}_{2}=1
\end{aligned}
$$

\section{Multi objective problem statement}

The multi objective problems considered in this study are reduction in sum of voltage deviation; voltage stability enhancement (reduction in sum of VCPI); minimisation of active and reactive power losses.

\subsection{Sum of voltage deviation index $\left(F_{1}\right)$}

It is aspiration to keep the voltage deviations in load side within $\pm 5 \%$. The first objective is to minimise summation of voltage variation (VV) of load buses (PQ bus) and denoted are given below.

$$
\begin{aligned}
& \mathrm{VV}_{\mathrm{g}} \begin{cases}0, & \text { if } 0.95 \leq \mathrm{V}_{1} \leq 1.05 \\
\left(1-\mathrm{V}_{1}\right)^{2} * \mathrm{C}, & \text { if } 0.9 \leq \mathrm{V}_{1} \leq 0.95 \text { or } 1.05 \leq \mathrm{V}_{1} \leq 1.1\end{cases} \\
& \mathrm{VDI}=\sum_{\mathrm{l}=1}^{1=\mathrm{N}_{\mathrm{PQ}}}\left(\mathrm{VV}_{\mathrm{g}}\right)
\end{aligned}
$$

where $\mathrm{V}_{1}$ - voltage magnitude at load bus 1; $\mathrm{C}$ - a small positive constant; $\mathrm{N}_{\mathrm{PQ}}$ - total number of load buses; VV - sum of voltage variation index. 


\subsection{Minimisation of sum of VCPI $\left(F_{2}\right)$}

The voltage stability is one of the paramount issues in electric utilities. VCPI is an effective quantitative measurement for the system to find the current states of the system how far it is from voltage collapse point. For this aim, the minimisation of the total VCPI $\left(\mathrm{VCPI}_{\mathrm{T}}\right)$ is proposed as second objective function to enhance the overall voltage stability of the system. The $\mathrm{VCPI}_{\mathrm{T}}$ is the sum of the voltage stability indices for all the lines of the system. To enhance voltage stability, the third objective function is to minimise the sum of voltage stability index value. The problem can be stated mathematically shown below:

$$
\mathrm{VCPI}_{\mathrm{T}}=\sum_{\substack{\mathrm{a}=1 \\ \mathrm{a}=\mathrm{PQbus}}}^{\mathrm{a}=\mathrm{N}_{\mathrm{PQ}}}\left(\mathrm{VCPI}_{\mathrm{a}}\right)
$$

\subsection{Minimisation of active power loss $\left(F_{3}\right)$}

$$
\mathrm{RP}_{-} \mathrm{L}=\sum_{\mathrm{i}=1}^{\mathrm{i}=\mathrm{N}_{\mathrm{br}}} \mathrm{G}_{\mathrm{ab}}\left(\mathrm{V}_{\mathrm{a}}^{2}+\mathrm{V}_{\mathrm{b}}^{2}-2 \mathrm{~V}_{\mathrm{a}} \mathrm{V}_{\mathrm{b}} \cos \left(\delta_{\mathrm{a}}-\delta_{\mathrm{b}}\right)\right)
$$

RP_L active power loss

$\mathrm{G}_{\mathrm{ab}} \quad$ conductance of the branch $\mathrm{a}-\mathrm{b}$

$\delta_{\mathrm{a}}-\delta_{\mathrm{b}} \quad$ load angle at bus a and $\mathrm{b}$.

\subsection{Minimisation of reactive power loss $\left(F_{4}\right)$}

The fourth objective function is to diminish total reactive power loss of the power network is listed as follows:

$$
\mathrm{QPL}=\sum_{\mathrm{i}=1}^{\mathrm{i}=\mathrm{N}_{\mathrm{br}}} \mathrm{B}_{\mathrm{ab}}\left(\mathrm{V}_{\mathrm{a}}^{2}+\mathrm{V}_{\mathrm{b}}^{2}-2 \mathrm{~V}_{\mathrm{a}} \mathrm{V}_{\mathrm{b}} \sin \left(\delta_{\mathrm{a}}-\delta_{\mathrm{b}}\right)\right)
$$

QPL reactive power loss

$\mathrm{B}_{\mathrm{ab}} \quad$ susceptance of the branch $\mathrm{a}-\mathrm{b}$

$\delta_{\mathrm{a}}-\delta_{\mathrm{b}} \quad$ load angle at bus a and $\mathrm{b}$.

$$
\text { Overall objective function (f) }=\operatorname{Min}\left(F_{1}+F_{2}+F_{3}+F_{4}\right)
$$

The objective functions $\mathrm{f}$ is subjected to the following equality constraint:

$$
\begin{aligned}
& \mathrm{P}_{\mathrm{ga}}-\mathrm{P}_{\mathrm{da}}-\left|\mathrm{V}_{\mathrm{a}} \sum_{\mathrm{a}=1}^{\mathrm{NB}} \mathrm{V}_{\mathrm{b}}\right|\left(\mathrm{G}_{\mathrm{ab}} \cos \theta_{\mathrm{ab}}+\mathrm{B}_{\mathrm{ab}} \sin \theta_{\mathrm{ab}}\right)=0 \\
& \mathrm{Q}_{\mathrm{ga}}-\mathrm{Q}_{\mathrm{da}}-\left|\mathrm{V}_{\mathrm{a}} \sum_{\mathrm{a}=1}^{\mathrm{NB}} \mathrm{V}_{\mathrm{b}}\right|\left(\mathrm{G}_{\mathrm{ab}} \sin \theta_{\mathrm{ab}}+\mathrm{B}_{\mathrm{ab}} \cos \theta_{\mathrm{ab}}\right)=0
\end{aligned}
$$


The objective functions f subjected to the following inequality constraint:

$$
\begin{array}{ll}
\mathrm{P}_{\mathrm{ga}}^{\min } \leq \mathrm{P}_{\mathrm{ga}} \leq \mathrm{P}_{\mathrm{ga}}^{\max } & \text { for } \mathrm{a}=1,2, \ldots, \mathrm{n} \text { generator bus } \\
\mathrm{Q}_{\mathrm{ga}}^{\min } \leq \mathrm{Q}_{\mathrm{ga}} \leq \mathrm{Q}_{\mathrm{ga}}^{\max } & \text { for } \mathrm{a}=1,2, \ldots, \mathrm{n} \text { generator bus }
\end{array}
$$

Bus voltage limits:

$$
\begin{array}{ll}
0.95 \leq \mathrm{V}_{\mathrm{a}} \leq 1.05 & \text { for } \mathrm{c}=1,2, \ldots, \mathrm{n} \text { load bus } \\
0.95 \leq \mathrm{V}_{\mathrm{a}} \leq 1.1 & \text { for } \mathrm{c}=1,2, \ldots, \mathrm{n} \text { generator bus }
\end{array}
$$

Susceptance of STATCOM constraint:

$-0.9 \leq \mathrm{B}_{\mathrm{STATCOM}} \leq 0.9$ in p.u

$\mathrm{B}_{\mathrm{STATCOM}}=$ Susceptance added to the bus by STATCOM

The objective value of the each particle in the swarm should be within a feasible range.

- $\quad \mathrm{Y}_{\mathrm{ab}}$ and $\theta_{\mathrm{ab}}$ are the magnitude and phase angle of bus admittance matrix

- $\quad \mathrm{P}_{\mathrm{ab}}$ and $\mathrm{Q}_{\mathrm{ab}}$ are the active and reactive power generation at line $\mathrm{a}$ and $\mathrm{b}$

- $\quad \mathrm{V}_{\mathrm{c}}$ and $\mathrm{V}_{\mathrm{d}}$ are the voltage magnitude at bus $\mathrm{c}$ and bus $\mathrm{d}$

- B $_{\text {STATCOM }}$ is susceptance added to the bus by STATCOM.

Prior to estimating the value of the fitness function value of a particle, the susceptance assessment of STATCOM must satisfy the constraints.

\section{Norms to be followed before placing the device}

a Few norms should be followed before the placement of STATCOM at buses of a given network.

b Locating STATCOMs at generator buses is not reasonable since automatic voltage regulators (AVR) controls the generator bus voltages. Therefore, the proposed algorithm prevents the installation of STATCOM(s) at generator buses. More than one STATCOM cannot be permitted to install at same load bus.

\section{Particle swarm optimisation}

Particle swarm optimisation (PSO) is a population-based evolutionary algorithm (Rajnarayanan, 2010). Its population is called a swarm and each individual spelled as particle. The tuneable parameters such as population size, learning factors, constriction factor, inertia weight, have great outcome in convergence. In this article, to enhance the convergence behaviour, dynamic adjustments of PSO parameters are recommended instead of enduring value. 


\section{Development of the proposed constriction factor PSO}

Clerc and Kennedy (2002) made changes in velocity updated equation by adding a new term called constriction factor to avoid early convergence in the optimisation process. To improve the excellence of constrained PSO called constriction factor PSO (CFPSO), a modification has made in velocity equation of the particle. The velocity and position of the particle are represented below:

$$
\begin{aligned}
\mathrm{V}^{1}[]= & \mathrm{CF}\left\{\mathrm{W} * \mathrm{~V}[]+\mathrm{C}_{1} * \mathrm{UR}_{(0,1)} *\left(\mathrm{P}_{\text {best }}[]-\mathrm{X}[]\right)\right. \\
& \left.+\mathrm{C}_{2} * \mathrm{UR}_{(0,1)} *\left(\mathrm{G}_{\text {best }}[]-\mathrm{X}[]\right)\right\} \\
\mathrm{X}^{1}[]= & \mathrm{X}[]+\mathrm{V}^{1}[] \\
\mathrm{V}_{\max 1} \leq \mathrm{V}^{1}[] \leq \mathrm{V}_{\min 1} & \\
\mathrm{C}_{-} \mathrm{F}= & \frac{2}{\left|2-\rho-\sqrt{\rho^{2}-4 * \rho}\right|}
\end{aligned}
$$

where $\rho=C_{1}+C_{2}, 4.1 \leq \rho \leq 4.2$.

$$
\mathrm{C}_{1}=\left(\mathrm{C}_{1 \mathrm{e}}-\mathrm{C}_{1 \mathrm{~s}}\right) * \frac{\text { Pre_run }}{\text { max_run }}+\mathrm{C}_{1 \mathrm{~s}}, \quad \mathrm{C}_{2}=\left(\mathrm{C}_{2 \mathrm{e}}-\mathrm{C}_{2 \mathrm{~s}}\right) * \frac{\text { Pre_run }}{\text { max_run }}+\mathrm{C}_{2 \mathrm{~s}}
$$

- $\mathrm{V}[\mathrm{]}$ and $\mathrm{X}[\mathrm{]}$ - velocity and position of the particle of present generation

- $\mathrm{W}$ - inertia weight of the particle

- $\mathrm{V}^{1}[]$ and $\mathrm{X}^{1}[]$ - velocity and position of the particle in next generation

- $\quad \mathrm{P}_{\text {best }}[\mathrm{]}$ - particle with best objective value in the present generation

- $\mathrm{G}_{\text {best }}[\mathrm{]}$ - particle with best objective value until the present generation

- $\mathrm{UR}_{(0,1)}$ - random numbers generated between zero and one.

\section{Search procedure of the proposed constriction factor PSO}

Step 1 Run load flow analysis using N-R method. Identify most severe generator outage using UI.

Step 2 Initialisation process

Initialise position vectors $\mathrm{x}[\mathrm{i}]$ and velocity vectors $\mathrm{v}[\mathrm{i}]$ randomly within the permissible range.

$$
\mathrm{V}_{\text {max_1 }}=\mathrm{b}\left(\frac{\mathrm{V}_{\text {high }}-\mathrm{V}_{\text {low }}}{2}\right) ; \quad \mathrm{V}_{\text {min_1 }}=-\mathrm{b}\left(\frac{\mathrm{V}_{\text {high }}-\mathrm{V}_{\text {low }}}{2}\right)
$$

- $\mathrm{V}_{\text {max_1 }}$ and $\mathrm{V}_{\text {min_1 }}-$ particle's maximum and minimum velocity boundary

- $b$ - scaling factor 
- $\quad \mathrm{V}_{\text {high }}$ and $\mathrm{V}_{\text {low }}$ - sum of maximum voltage limit and minimum voltage limit of load bus.

From this load flow data, calculate the objective function of $\mathrm{X}[\mathrm{]}$ of each particle and assign the obj_value[ ] to each particle.

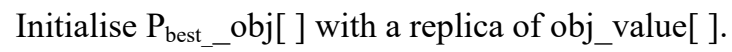

Initialise Gbest[ ] with a index of a particle with minimum fitness value.

Check the termination criteria if yes the $\mathrm{G}_{\text {best }}$ value and terminate the process.

This latest $G_{\text {best }}$ value is the minimum objective value of the problem statement satisfying with all constraints.

Step 3 Evaluation process

Repeat the process mentioned below until termination criteria is attained.

For each particle in the swarm

Calculate objective value from load flow analysis.

First comparison

If the objective value is lower than the best objective value

$\mathrm{P}_{\text {best }}[]$ then,

$$
\begin{aligned}
& \mathrm{P}_{\text {best }}[]=\mathrm{x}[\mathrm{]} \text { and } \\
& \mathrm{P}_{\text {best_obj[ }}[\mathrm{]}=\text { obj_value[ ]. }
\end{aligned}
$$

End

Second comparison

Compare the fitness value with the population's overall previous best. If the current value is better than $\mathrm{G}_{\text {best }}$, then reset $\mathrm{G}_{\text {best }}$ to the current particle's array index and value.

Set iteration count.

Step 4 Updating process

For each particle

Update particle velocity vector according to equation (10). Check the minimum and maximum velocity value of the particle within the allowable limit.

If satisfied, then calculate particle position vector according to (11). This modified particle's position should satisfy the susceptance of STATCOM constraint.

Step 5 This modified position of the particle (from step 4) is taken as initial value for $\mathrm{N}-\mathrm{R}$ load flow with $(\mathrm{N}-1)$ line is considered. Compute line losses, voltage parameter on each load bus and line flows. Calculate the objective function. 
If the current $G_{\text {best }}$ value is better than the $G_{\text {best }}$ value in step 2, current fitness value is set to $G_{\text {best. }}$ Similarly, the present $P_{\text {best }}$ value is better than the value in step 2, present $\mathrm{P}_{\text {best }}$ value has chosen to $\mathrm{P}_{\text {best }}$. If the stopping criteria have not been satisfied, increase the iteration count and go to step 3, or else display the $\mathrm{G}_{\text {best }}$ value and terminate the process.

Terminating criteria (Varadarajan and Swarup, 2008; Jayachitra, 2018)

The terminating criteria are related to nature of the problem. The iterative process will be discontinued whenever one of the following criteria is met:

1 an expected solution has been arrived

2 no further improvement in solution

3 control variables taken into account have converged to a steady value

4 predefined maximum number of allowable generation has been reached.

Mutation is a background operator, which introduces some sort of artificial diversification in the population to avoid premature convergence to local optimum (i.e., to enhance the probability of escaping from a local optimum.).

After several runs, the input control parameters are listed in Table 1 are found to be the best for the optimal performance of the different algorithms. The optimal location and setting of the TCSC can be obtained by solving optimisation algorithms with maximum number. of generation of 100 . After several runs, the input control parameters are listed in Table 1 are found to be the best for the optimal performance of the different algorithms.

Table 1 Initial parameter values of various methods

\begin{tabular}{lcccc}
\hline Control parameter & PSO & CFPSO & CM-CFPSO & GM-CFPSO \\
\hline \multicolumn{5}{c}{ Population size $-10,25$ and 50} \\
Max. no. of generation -100 \\
\hline $\mathrm{C}_{1}$ & 2 & $\mathrm{C}_{1 \mathrm{~s}}=2.5$ & $\mathrm{C}_{1 \mathrm{~s}}=2.5$ & $\mathrm{C}_{1 \mathrm{~s}}=2.5$ \\
& - & $\mathrm{C}_{1 \mathrm{e}}=0.5$ & $\mathrm{C}_{1 \mathrm{e}}=0.5$ & $\mathrm{C}_{1 \mathrm{e}}=0.5$ \\
\hline $\mathrm{C}_{2}$ & 2 & $\mathrm{C}_{2 \mathrm{~s}}=0.5$ & $\mathrm{C}_{2 \mathrm{~s}}=0.5$ & $\mathrm{C}_{2 \mathrm{~s}}=0.5$ \\
& - & $\mathrm{C}_{2 \mathrm{e}}=2.5$ & $\mathrm{C}_{2 \mathrm{e}}=2.5$ & $\mathrm{C}_{2 \mathrm{e}}=2.5$ \\
\hline
\end{tabular}

\section{Search procedure of the Cauchy mutation-CFPSO approach}

Steps 1 to 5 and termination criteria are analogous to earlier approach. An alteration had been executed in step 5 .

Step 6 The modification in search point was initiated from the each particle by extending each component with a Cauchy random variable with zero mean and standard deviation proportional to scaled cost values as given in (15).

$\mathrm{X}^{\prime}[]=\mathrm{X}[]+\sigma_{\mathrm{i}}^{2} \mathrm{C}_{\mathrm{i}}(0,1)$

where $\mathrm{C}_{\mathrm{i}}$ is a Cauchy random variable with a scale parameter with $\mathrm{t}=1$ centred at zero. This variable has mean of zero and a standard deviation of $\sigma_{\mathrm{i}}$. 
The modified position of the particle (from step 4) is acknowledged as initial value for $\mathrm{N}-\mathrm{R}$ load flow with $(\mathrm{N}-1)$ lines is considered.

Compute line losses, voltage parameter on each load bus and line flows. Calculate the objective value.

If the current $G_{\text {best }}$ value is superior to $G_{\text {best }}$ value in step 2 then, current objective value is fixed to $\mathrm{G}_{\text {best. }}$.

Similarly, the present $P_{\text {best }}$ value is superior to the value in step 2, present $P_{\text {best }}$ value had been chosen to $P_{\text {best }}$.

If the stopping criterion is not yet satisfied, increase the iteration count and go to step 3, or else display latest $\mathrm{G}_{\text {best }}$ value and discontinue the process.

The latest value of $\mathrm{G}_{\text {best }}$ is the minimum objective value of the problem statement satisfying with all constraints and the terminating criteria are similar to previous approach.

\section{Search procedure of the Gaussian mutation-CFPSO approach}

Steps 1 to 5 and termination criteria are analogous to earlier approach. An alteration had been executed in step 5 .

Step 6 The modification in search point is initiated from the each particle by extending each component with Gaussian random variable with zero mean and standard deviation proportional to scaled cost values as shown in (16).

$$
\mathrm{X}^{\prime}[]=\mathrm{X}[]+\mathrm{N}_{\mathrm{i}}\left(0, \sigma_{\mathrm{i}}^{2}\right)
$$

where $\mathrm{N}_{\mathrm{i}}$ is a Gaussian random variable with mean of zero a standard deviation of $\sigma_{\mathrm{i}}$.

The modified position of the particle (from step 4) is acknowledged as initial value for $\mathrm{N}-\mathrm{R}$ load flow with $(\mathrm{N}-1)$ line is considered.

Compute line losses, voltage parameter on each load bus and line flows.

Calculate the objective value. If the current $G_{\text {best }}$ value is superior to $G_{\text {best }}$ value in step 2 then, current objective value is fixed to $G_{\text {best }}$.

Similarly, the present $P_{\text {best }}$ value is superior to the value in step 2, present $P_{\text {best }}$ value had been chosen to $P_{\text {best }}$. If the stopping criterion is not yet satisfied, increase the iteration count and go to step 3, or else display latest $\mathrm{G}_{\text {best }}$ value and discontinue the process.

The latest value of $\mathrm{G}_{\text {best }}$ is the minimum objective value of the problem statement satisfying with all constraints and the terminating criteria are similar to previous approach. 


\section{Results and interpretation - case study IEEE 30 bus system}

An IEEE 30 bus system has totally five generator buses namely 2, 5, 8, 11 and 13 and 41 transmission lines. Each of the five generator buses had been isolated from the network sequentially for the purpose of contingency analysis. Using N-R power flow method, the performance of the generator outage had been indexed in Table 2. It was noticed that, for instance, removal of generator bus number 11, the branch 2-5 had the zenith UI value, was the severe-most line of the 30 bus system. However, bus 2 and 5 are generator buses. In this research study, as per the thumb rule mentioned for choosing the location to install STATCOM, it should be at load bus. According to the rule for best location, the second most severe line 23-24 is taken from Table 3. The STATCOM is located at bus number 23 gives best result among them.

Table 2 Generator contingency analysis

\begin{tabular}{lcc}
\hline S. no. & Generator bus number & Summation of UI \\
\hline 1 & 2 & 0.261 \\
2 & 5 & 0.262 \\
3 & 8 & 0.2601 \\
4 & 11 & 0.263 \\
5 & 13 & 0.2609 \\
\hline
\end{tabular}

The impact of STATCOM on voltage magnitudes and voltage angles of IEEE 30 bus system during absence and existence of STATCOM (post outage of generator bus number 11) as shown in Figure 1. From Figure 1, it was concluded that, in bus number 26 and 30 the terminal voltage profile is enlarged from 0.992 and 0.986 to 1.001 and 0.999 respectively after installation of STATCOM.

Figure 1 Voltage profile of IEEE 30 bus system under different scenarios (see online version for colours)

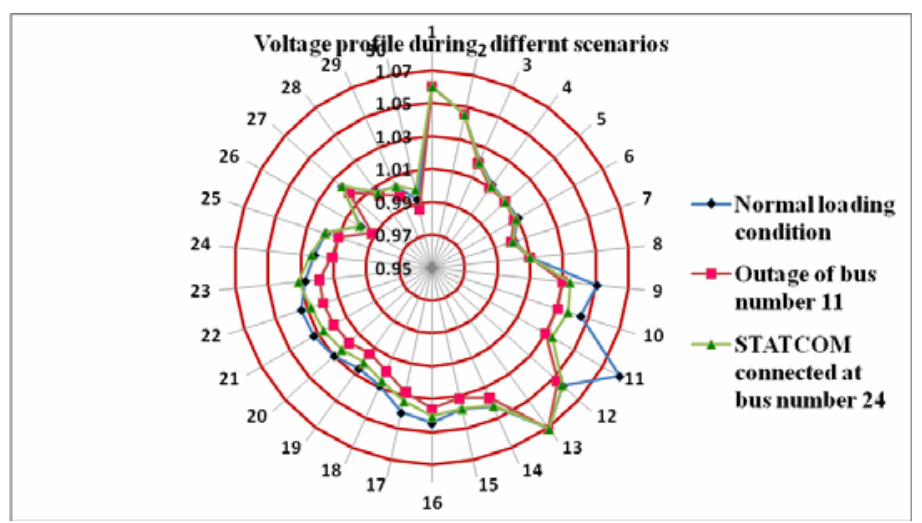

The STATCOM parameter had been fine-tuned using PSO and with mutation. The outcomes with populations 50 had been submitted in Table 4. It was concerned that due to outage of generator 11 , the total active and reactive power loss boosted from 17.56 MW and 67.69 MVAR to 17.67 MW and 67.715 MVAr respectively. After the placement of STATCOM at bus number 24 , with reference to population size of 50, using 
PSO, CFPSO and Cauchy mutation-CFPSO (CM-CFPSO) the active power losses reduce to $15.81 \mathrm{MW}, 15.61 \mathrm{MW}$ and $15.49 \mathrm{MW}$ respectively. Similarly the reactive power reduction was such that 65.75 MVAr, 65.54 MVAr and 65.41 MVAr. Tuning of STATCOM using Gaussian mutation-CFPSO (GM-CFPSO) further reduced the losses to 14.94 MW and 65.01 MVAr respectively. Similarly, other parameters of the system also condensed to minimum values when PSO and with mutation had been implemented for tuning the STATCOM.

Table 3 Generator Contingency analysis (outage of bus no. 11)

\begin{tabular}{lccc}
\hline \multirow{2}{*}{ no. } & \multicolumn{2}{c}{ Transmission line } & \multirow{2}{*}{$\sum U I$} \\
\cline { 2 - 3 } & Starting bus & Ending bus & 0.036 \\
\hline 1 & 2 & 5 & 0.022 \\
3 & 23 & 24 & 0.019 \\
4 & 4 & 12 & 0.016 \\
5 & 22 & 24 & 0.014 \\
\hline
\end{tabular}

Figure 2 Voltage stability improvements after optimisation (different approaches in 30 bus system) (see online version for colours)

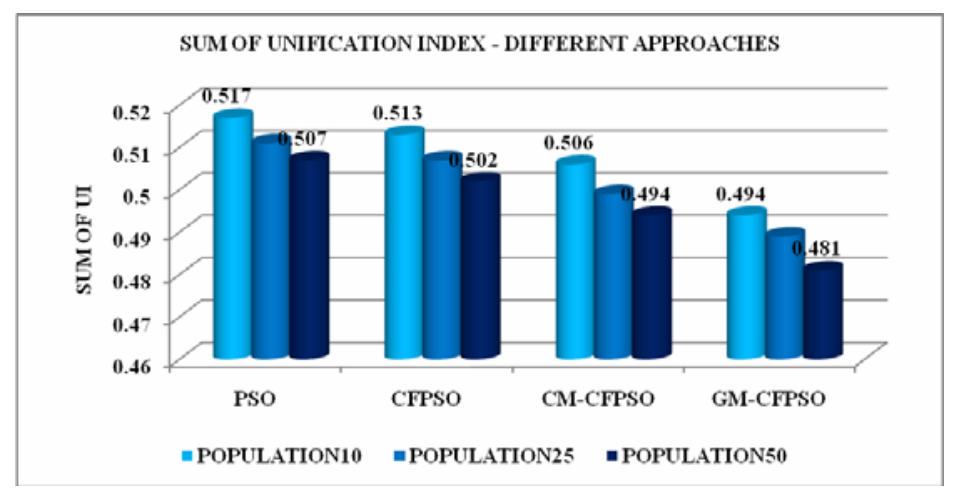

The study of Table 4 it was interpreted that, GM-CFPSO obtained best power loss reduction, power saving, progress in stability margin compared with other approaches. The graphical analyses of the stability margin improvement and reduction in summation of voltage deviation index had been represented in Figure 2. Based on the population size of 50, the traditional PSO obtained power loss reduction of $9.96 \%$, CFPSO attained power loss reduction of $11.1 \%$, with CM-CFPSO power loss reduction of $11.8 \%$ and GM-CFPSO achieved power loss reduction of $14.92 \%$ from the initial system loss. Even though the GM-CFPSO took more execution time than traditional PSO and CFPSO but less iteration compared to other techniques to converge, the optimal solution achieved by GM-CFPSO is superior to others. The graphical analyses of the power loss minimisation are illustrated in Figures 3 and 4. It was observed that, using GM-CFPSO the amount of real and reactive power saving are 2,730 KW and 2,705 KVAr respectively. Among all, GM-CFPSO method reduced power loss hence power generation also minimised analogised with other approaches. 
Table 4 Comparison of system parameters based on population size 10, 25 and 50 with various approaches

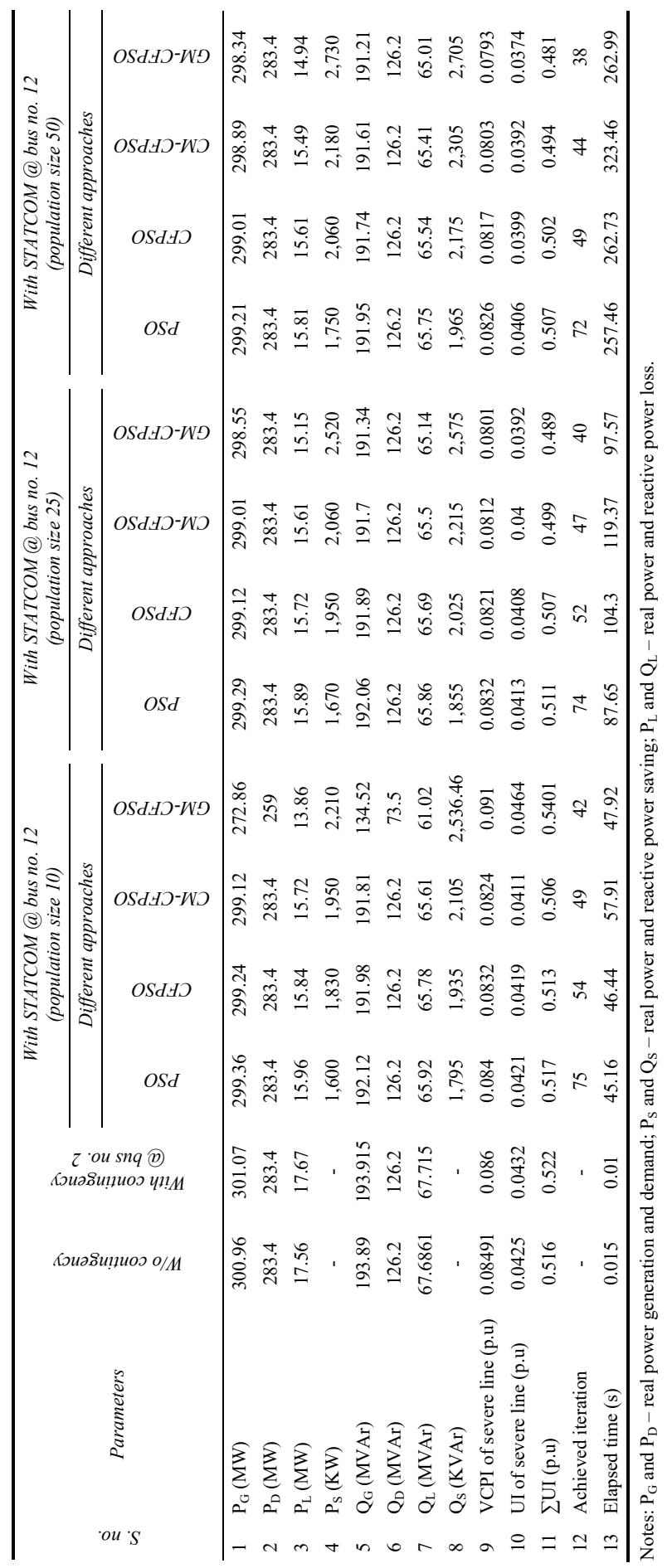


Figure 3 (a) Reactive power loss minimisation after optimisation - different approaches in 30 bus system (b) Real and reactive power loss minimisation after optimisation - different approaches in 30 bus system (see online version for colours)

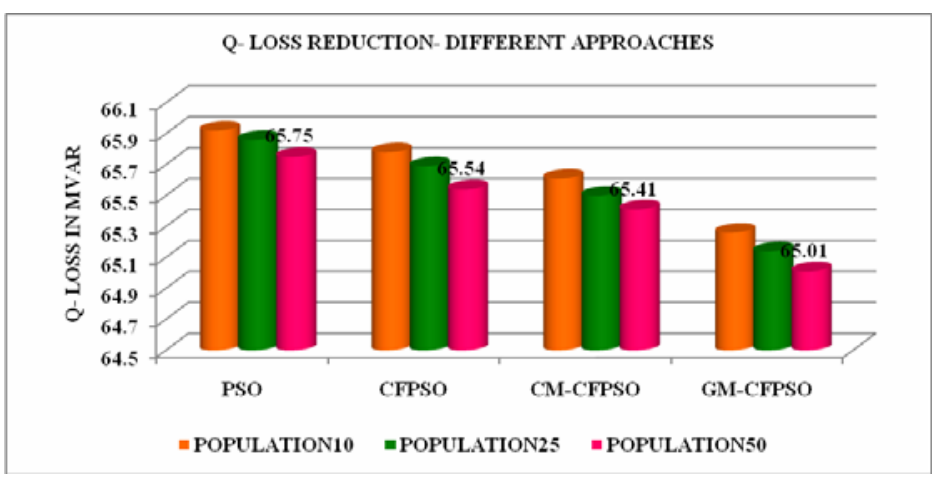

(a)

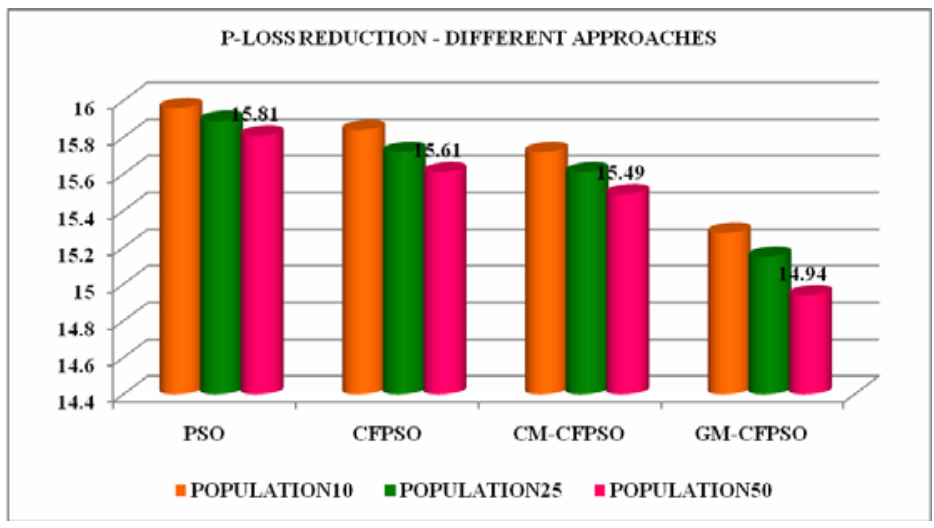

(b)

Figure 4 (a) Reactive power saving after optimisation - different approaches in 30 bus system (b) Real and reactive power saving after optimisation - different approaches in 30 bus system (see online version for colours)

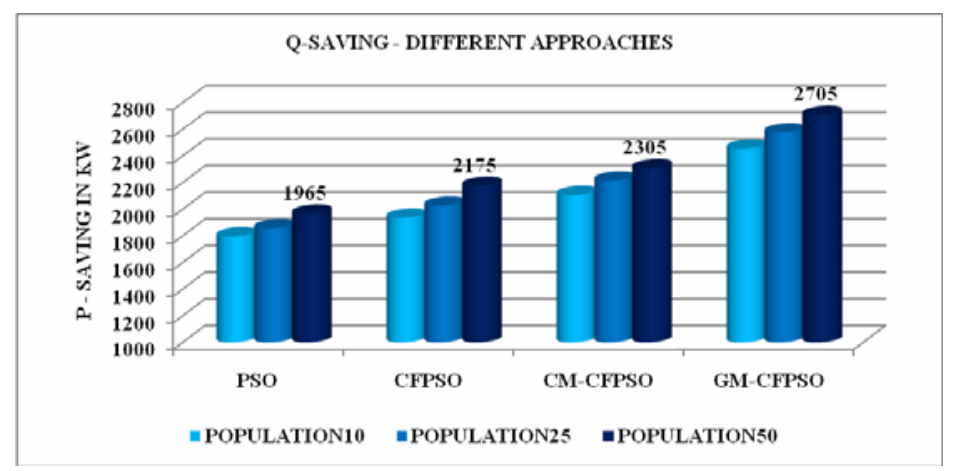

(a) 
Figure 4 (a) Reactive power saving after optimisation - different approaches in 30 bus system (b) Real and reactive power saving after optimisation - different approaches in 30 bus system (continued) (see online version for colours)

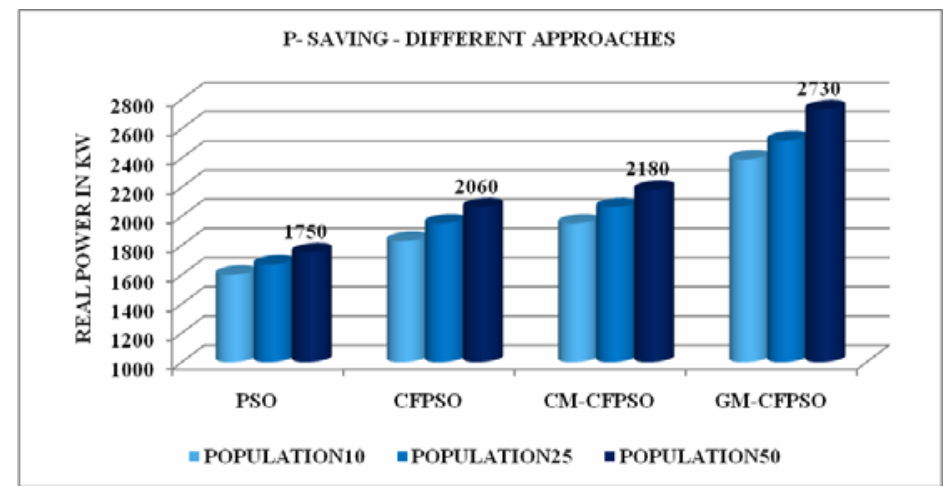

(b)

The outcomes of optimal location and rating of STATCOM had been observed for different load scenarios for IEEE 30 bus system using PSO, CFPSO, CM-CFPSO and GM-CFPSO approaches and it is shown in Table 5.

Table 5 Optimal placement and susceptance (B) rating of STATCOM during generator contingency

\begin{tabular}{|c|c|c|c|c|c|c|c|c|}
\hline \multirow{2}{*}{$\begin{array}{l}\text { Generator } \\
\text { bus outage }\end{array}$} & \multicolumn{2}{|c|}{ PSO } & \multicolumn{2}{|c|}{ CFPSO } & \multicolumn{2}{|c|}{ CM-CFPSO } & \multicolumn{2}{|c|}{ GM-CFPSO } \\
\hline & Location & $\begin{array}{c}\text { B-rating } \\
\text { (p.u) }\end{array}$ & Location & $\begin{array}{c}\text { B-rating } \\
\text { (p.u) }\end{array}$ & Location & $\begin{array}{c}\text { B-rating } \\
\text { (p.u) }\end{array}$ & Location & $\begin{array}{c}\text { B-rating } \\
(p . u)\end{array}$ \\
\hline $\begin{array}{l}\text { Outage of } \\
\text { PV bus } 11\end{array}$ & 23 & 0.0235 & 23 & 0.0214 & 24 & 0.0208 & 24 & 0.0193 \\
\hline
\end{tabular}

Figure 5 Convergence histories of best solutions of different approaches after installation of STATCOM (see online version for colours)
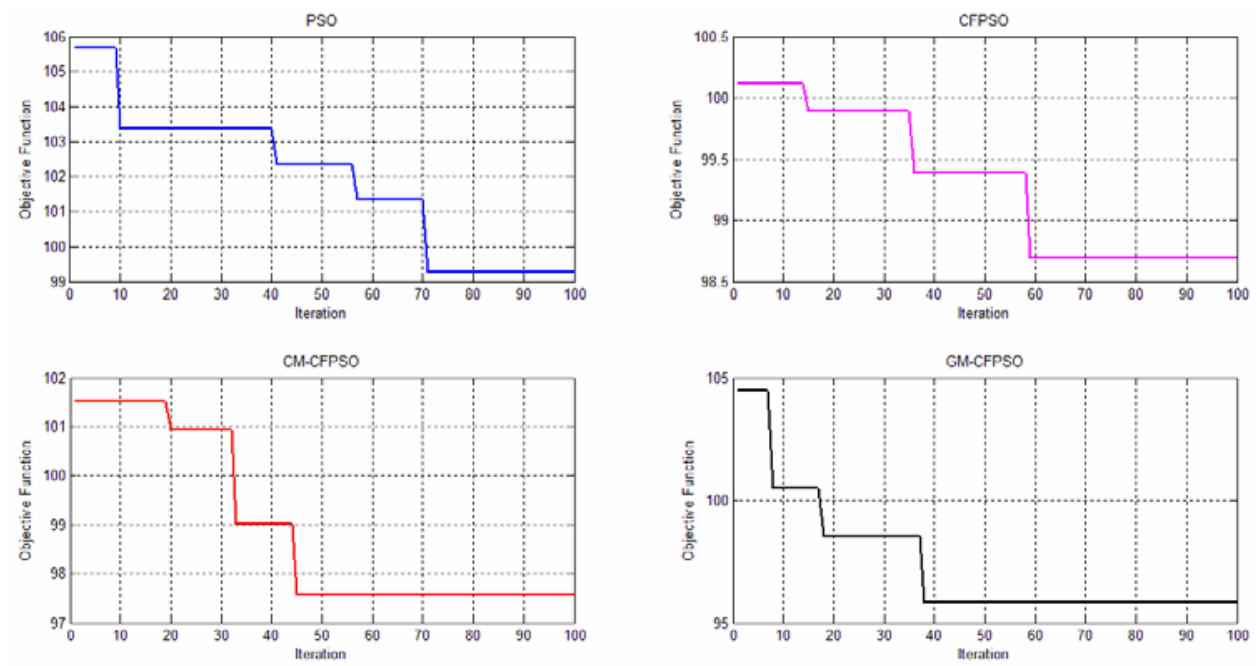
Figure 5 illustrated the graphical analysis results of convergence properties (objective function verses iteration) of the competitors. It was scrutinised that the objective function was gradually reduced as the iteration count had been increased. At the end of the each approach, it converged with minimum objective value, i.e., the optimal location and size of STATCOM for each case. The conventional PSO converged at 71 st iterations, achieving least objective value of 99.2. The CFPSO approach converged quicker than the conventional PSO (at 58th iterations), achieving objective value of 98.7. But, CM-CFPSO algorithms converge quickly with a minimum objective value of 97.6 at 44th iterations, respectively. The GM-CFPSO is the fastest among all competitors achieving with minimum objective value of 95.8 at 40 th run of 38 th iteration.

\section{Conclusions}

An attempt had been made to minimise the real power loss and sum of voltage deviation and enhance voltage stability margin by using shunt family FACTS device-STATCOM during outage of generator bus. This device had been fixed at most severe bus via PSO; CFPSO and GM-CFPSO had been presented. The most severe buses were identified by using a novel approach called unification index (UI). MATLAB codes for PSO, CFPSO and GM-CFPSO optimisation techniques were developed to identify the appropriate location and sizing of STATCOM in order to achieve the objectives. The PSO approach basically has three major control parameters:

1 population size

2 learning factor

3 inertia weight.

The causes of varying the control parameters on the performance of PSO were studied. The effectiveness of the proposed GM-CFPSO approach had been verified on a standard IEEE 30-bus system. The comparative result shows the proposed approach is competent.

\section{References}

Banu, R.N. and Devaraj, D. (2009) 'Enhanced genetic algorithm approach for security constrained optimal power flow including FACTS devices', International Journal of Electrical and Electronics Engineering, Vol. 3, No. 4, pp.552-557.

Clerc, M. and Kennedy, J. (2002) 'The particle swarm-explosion, stability, and convergence in a multidimensional complex space', IEEE Trans. on Evolutionary Computation, Vol. 6, No. 1, pp.58-73.

Gitizadeh, M. and Kalantar, M. (2008) 'A new approach for congestion management via optimal location of FACTS devices in deregulated power systems', Third International Conference on Electric Utility Deregulation and Restructuring and Power Technologies, 2008. DRPT 2008, IEEE.

Jayachitra, S. (2018) 'Application of mutation inspired constrained factor PSO considering voltage stability and losses by locating and rating TCSC during N-1 contingency', Vol. 10, Nos. 3-4, pp.174-182.

Malathy, P. and Shunmugalatha, A. (2016) 'Loadability analysis during single contingency with FACTS devices using differential evolution', 2016 IEEE 6th International Conference on Power Systems (ICPS), pp.1-6, IEEE. 
Mishra, A. and Gundavarapu, V.N.K. (2016) 'Contingency management of power system with interline power flow controller using real power performance index and line stability index', Ain Shams Engineering Journal, Vol. 7, No. 1, pp.209-222.

Mishra, A., Kumar, G.V.N., Rao, B.V., Chowdary, D.D. and Phanidhar, S.V. (2016) 'Firefly algorithm based generator contingency management using an interline power flow controller', IJCTA, Vol. 9, No. 32, pp.29-37.

Naishan, H., Xu, T. and Qinghua, L. (2006) 'The analysis of abundance index of voltage stability based circuit theory', Guangxi Electric Power, February, Vol. 1, No. 2, pp.12-14.

Paserba, J.J. (2010) 'How facts controllers benefit ac transmission systems - phases of power system studies', Transmission and Distribution Conference and Exposition, 2010 IEEE PES, p.1.

Preethi, V.A., Muralidharan, S. and Rajasekar, S. (2011) 'Application of genetic algorithm to power system voltage stability enhancement using facts devices', 2011 International Conference on Recent Advancements in Electrical, Electronics and Control Engineering (ICONRAEeCE), IEEE.

Rajnarayanan, P.N. (2010) Application and comparison of Meta-Heuristic Techniques to Optimal Reactive Power Dispatch, PhD title, April, Anna University.

Roy, P.K., Ghoshal, S.P. and Thakur, S.S. (2011) 'Optimal reactive power dispatch considering flexible AC transmission system devices using biogeography-based optimization', Electric Power Components and Systems, Vol. 39, No. 8, pp.733-750.

Sundar, K.S. and Ravikumar, H.M. (2012) 'Selection of TCSC location for secured optimal power flow under normal and network contingencies', International Journal of Electrical Power \& Energy Systems, Vol. 34, No. 1, pp.29-37.

Varadarajan, M. and Swarup, K.S. (2008) 'Volt-var optimization using differential evolution', Electric Power Components and Systems, Vol. 36, No. 4, pp.387-408. 